\title{
MATHEMATICAL MODEL FOR THERMAL PROCESSES IN PHOTOPOLYMERIZATION
}

\author{
Jaroslaw Siedlecki ${ }^{1}$, Mariusz Ciesielski ${ }^{2}$ \\ ${ }^{1}$ Institute of Mathematics, ${ }^{2}$ Institute of Computer and Information Sciences \\ Czestochowa University of Technology, Poland \\ jaroslaw.siedlecki@im.pcz.pl,mariusz.ciesielski@icis.pcz.pl
}

\begin{abstract}
In the paper the mathematical model for interaction of an intense light source on a photosensitive monomer/polymer mass with photoinitiator component is presented. Heat is released during the photopolymerization process. The thermal and photopolymerization processes occurring in the monomer/polymer mass which is located in the porcelain form are analysed. The equations of mathematical model in axially-symmetrical domain are solved numerically. In the work the effect of light dose on the processes is investigated. In the final part of this paper, the examples of computations are presented.
\end{abstract}

\section{Introduction}

In polymer chemistry, the process of polymerization [1] is related to linking small molecules (monomers) into a chain of larger molecules (polymers). The polymerization consists of three steps: initiation, propagation and termination. In photo-polymerization, this process is initiated by exposing photosensitive compounds (containing a photoinitiator) to an intense light source (i.e. light from a laser beam) whereby a photo-chemical process begins. A photoinitiator by reacting with an actinic photon decomposes into radicals which catalyse the polymerization process. Next, the reaction of the addition of the radical to a monomer molecule produces an initial activated monomer. In the second step (the propagation), the polymer chain is formed by reacting the activated monomer with other monomer. This step goes on (forming longer molecules) until a chain inhibition process terminates the polymerization reaction (the third step).

In the photo-polymerization, a temperature rise is observed which is caused by the exothermic reaction during the polymerization. Polymerization can be turned on and off by turning the light source off and on.

In this paper the mathematical models for the process of photo-polymerization are developed. In the models the changes in time of monomer and photoinitiator concentrations, the intensity of absorbed light by photoinitiator, the shape distribution of light source and the temperature profiles in the considered domain are taken into account. 


\section{Mathematical model}

The domain considered in Figure 1 is presented. The cylindrical domain is limited by planes $z=0$ and $z=Z$ and surface $r=R$. The domain consists of two subdomains: the monomer/polymer mass $\left(\Omega_{1}\right)$ and the porcelain form $\left(\Omega_{2}\right)$. The monomer/polymer mass is placed inside the porcelain form shaped as a cylinder of radius $R_{1}$ and height $Z_{1}$. On the upper surface limiting the domain, the stationary light spot on the photopolymerized material is exposed. The porcelain form play a role of an internal chill.

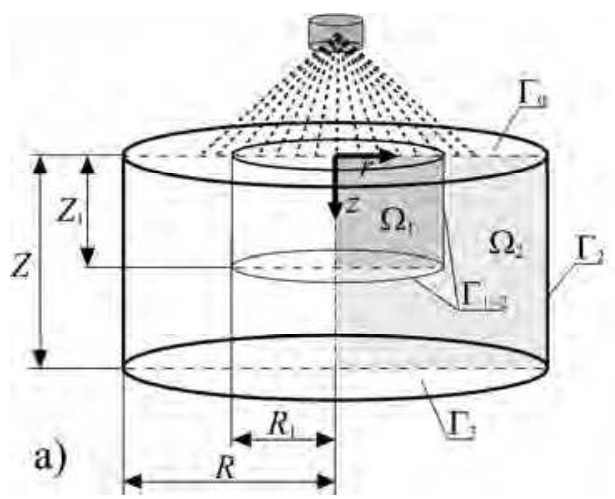

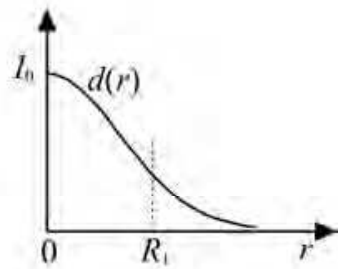

b)

Fig. 1. The domain considered (a) and the light distribution on the top surface (b)

The temperature field in the system of the monomer/polymer and the form is described by the system of equations [2]

$$
c_{m} \rho_{m} \frac{\partial T_{m}}{\partial t}=\lambda_{m} \nabla^{2} T_{m}+q_{m}
$$

where index $m=\{1,2\}$ identifies the monomer/polymer and the form sub-domain, respectively, $T=T(r, z, t)\left[{ }^{\circ} \mathrm{C}\right]$ is the temperature, $r, z[\mathrm{~m}], t[\mathrm{~s}]$ denote spatial coordinates and time, $c\left[\mathrm{~J} /\left(\mathrm{kg}^{\circ} \mathrm{C}\right)\right], \rho\left[\mathrm{kg} / \mathrm{m}^{3}\right], \lambda\left[\mathrm{W} /\left(\mathrm{m}^{\circ} \mathrm{C}\right)\right]$ are the specific heat, the density and the thermal conductivity of materials considered, respectively. The operator $\nabla^{2} T$ in the cylindrical domain is of the form

$$
\nabla^{2} T_{m}=\frac{1}{r} \frac{\partial}{\partial r}\left(r \frac{\partial T_{m}}{\partial r}\right)+\frac{\partial^{2} T_{m}}{\partial z^{2}}
$$

The term $q_{m}=q_{m}(r, z, t)\left[\mathrm{W} / \mathrm{m}^{3}\right]$ is a heat source function, and this term for $m=1$ can be written in the form [2]

$$
q_{1}=\Delta H_{p} R_{p}
$$


where $\Delta H_{p}[\mathrm{~J} / \mathrm{mol}]$ is the heat of polymerization and $R_{p}=R_{p}(r, z, t)\left[\mathrm{mol} /\left(\mathrm{m}^{3} \mathrm{~s}\right)\right]$ is the polymerization rate at the neighbourhood of the considered point $\{r, z\}$. Whereas, for $m=2$ we assume $q_{2}=0$.

The Eq. (1) is supplemented by the following initial-boundary conditions. For $t=0$ the initial condition is know

$$
\left.T_{m}\right|_{t=0}=T_{\text {init }}, \quad m=1,2
$$

On the contact surface between monomer/polymer and form, the IV type of boundary condition is assumed

$$
\Gamma_{1-2}:\left\{\begin{aligned}
-\lambda_{1} \frac{\partial T_{1}}{\partial n} & =-\lambda_{2} \frac{\partial T_{2}}{\partial n} \\
T_{1} & =T_{2}
\end{aligned}\right.
$$

where $\partial / \partial n$ is a normal derivative. On the external surface of the both sub-domains (see Fig. 1) the II and III types of boundary conditions are given

$$
\begin{gathered}
\Gamma_{0} \cup \Gamma_{2}:-\lambda_{m} \frac{\partial T_{m}}{\partial n}=-\alpha\left(T_{a m b}-T_{m}\right) \\
\Gamma_{3}: \frac{\partial T_{m}}{\partial n}=0 \\
\left.\frac{\partial T_{m}}{\partial r}\right|_{r=0}=0
\end{gathered}
$$

where $\alpha\left[\mathrm{W} /\left(\mathrm{m}^{2}{ }^{\circ} \mathrm{C}\right)\right]$ is the heat transfer coefficient and $T_{a m b}\left[{ }^{\circ} \mathrm{C}\right]$ is the ambient temperature.

On the boundary $\Gamma_{0}$, the stationary light spot on the photopolymerized material is exposed. The intensity distribution of this light $I=I(r, z, t)$ is given in the form

$$
\left.I\right|_{z=0}=I_{0} d(r) \Theta(t)
$$

where $I_{0}\left[\operatorname{Einstein} /\left(\mathrm{m}^{2} \mathrm{~s}\right)\right]$ is the intensity of the beam, $d(r)$ for $0 \leq r \leq R_{1}$ is a shape distribution function and $\Theta(t)$ determines variation light exposition in time (in this work the impulse light with duration time $\left[0, t_{0}\right]$ has been assumed: $\Theta(t)=H\left(t_{0}-t\right)$, where $H$ is the Heaviside function).

The light intensity decreases with depth into the monomer/polymer mass [1,3]. This is due to the light absorption by the photoinitiator. The rate of change of the light intensity with depth is

$$
\frac{\partial I}{\partial z}=-\varepsilon S I
$$


where $\varepsilon\left[\mathrm{m}^{2} / \mathrm{mol}\right]$ is the molar absorptivity constant for photoinitiator and $S=S(r, z, t)\left[\mathrm{mol} / \mathrm{m}^{3}\right]$ is the temporary concentration of photoinitiator at the considered point of the domain. The analytical solution of Eq. (10) with the boundary condition for $z=0$ (9) is of the form

$$
I=I_{0} d(r) \Theta(t) \exp (-\varepsilon S z)
$$

The intensity of the absorbed light $I_{a}=I_{a}(r, z, t)\left[\mathrm{mol} /\left(\mathrm{m}^{3} \mathrm{~s}\right)\right]$ is determined by the following relation

$$
I_{a}=\varepsilon S I
$$

In photopolymerization [1, 3], the rate of photochemical initiation $R_{i}=R_{i}(r, z, t)$ and the polymerization rate $R_{p}=R_{p}(r, z, t)$ play an important role. These rates are given as

$$
\begin{gathered}
R_{i}=\phi I_{a} \\
R_{p}=k_{p} M \sqrt{\frac{\phi I_{a}}{k_{t}}}
\end{gathered}
$$

where $\phi[-]$ is the quantum yield for initiation, $k_{p}\left[\mathrm{~m}^{3} /(\mathrm{mol} \mathrm{s})\right]$ and $k_{t}\left[\mathrm{~m}^{3} /(\mathrm{mol} \mathrm{s})\right]$ are the propagation and termination rate constants, respectively; and $M=M(r, z, t)$ $\left[\mathrm{mol} / \mathrm{m}^{3}\right]$ is the temporary monomer concentration.

The changes in time of monomer and photoinitiator concentrations are determined by the following equations

$$
\begin{aligned}
& \frac{\partial M}{\partial t}=-R_{p} \\
& \frac{\partial S}{\partial t}=-R_{i}
\end{aligned}
$$

with initial concentrations

$$
\left.M\right|_{t=0}=M_{\text {init }},\left.\quad S\right|_{t=0}=S_{\text {init }}
$$

\section{Examples of computations}

Numerical simulations of a thermal and photopolymerization processes for the material (1,6 hexanediol diacrylate - HDDA) located in the porcelain form have been executed. The considered domain has the dimensions: $R_{1}=2 \mathrm{~mm}, R=5 \mathrm{~mm}$, $Z_{1}=2 \mathrm{~mm}, Z=5 \mathrm{~mm}$. At the stage of numerical computations, the control volume method [4-6] has been used.

The following thermophysical parameters of HDDA [7] have been assumed: $c_{1}=1700 \mathrm{~J} /\left(\mathrm{kg}{ }^{\circ} \mathrm{C}\right), \rho_{1}=1150 \mathrm{~kg} / \mathrm{m}^{3}, \lambda_{1}=0.2 \mathrm{~W} /\left(\mathrm{m}^{\circ} \mathrm{C}\right), \Delta H_{p}=166 \mathrm{~kJ} / \mathrm{mol}$, 
$k_{p} /\left(k_{t}\right)^{1 / 2}=0.26\left(\mathrm{~m}^{3} /(\mathrm{mol} \mathrm{s})\right)^{1 / 2}, \varepsilon=20 \mathrm{~m}^{2} / \mathrm{mol}, \phi=0.1$, whereas thermophysical parameters of porcelain are the following: $c_{2}=2300 \mathrm{~J} /\left(\mathrm{kg}{ }^{\circ} \mathrm{C}\right), \rho_{2}=840 \mathrm{~kg} / \mathrm{m}^{3}$, $\lambda_{2}=1.3 \mathrm{~W} /\left(\mathrm{m}^{\circ} \mathrm{C}\right)$. The initial concentration of monomer and photoinitiator are $M_{\text {init }}=3 \mathrm{kmol} / \mathrm{m}^{3}, S_{\text {init }}=0.15 \mathrm{kmol} / \mathrm{m}^{3}$, the initial temperature is $T_{\text {init }}=20^{\circ} \mathrm{C}$, the ambient temperature is $T_{a m b}=20^{\circ} \mathrm{C}$ and the heat transfer coefficient is $\alpha=10 \mathrm{~W} /\left(\mathrm{m}^{2}{ }^{\circ} \mathrm{C}\right)$.

In simulations, the function of the distribution of light source on the top surface of the considered domain of the Gaussian shape $d(r)=\exp \left(-r^{2} / R_{1}^{2}\right)$ has been used. Two tests depending on the intensity and the duration of the light source have been considered.

In the first test the following values $I_{0}=0.5$ Einstein $/\left(\mathrm{m}^{2} \mathrm{~s}\right)$ and $t_{0}=0.25 \mathrm{~s}$ have been taken into account. In Figure 2 the profile of monomer conversion and isotherms in the monomer/polymer sub-domain at time $0.25 \mathrm{~s}$ are shown. The kinetics of changes of monomer conversion and temperature at four selected points in the monomer/polymer sub-domain in Figure 3 is presented. One can observe that after turn off of the light source, the photopolymerization is terminated and temperature of sub-domains reaches to the equilibrium state.

a)

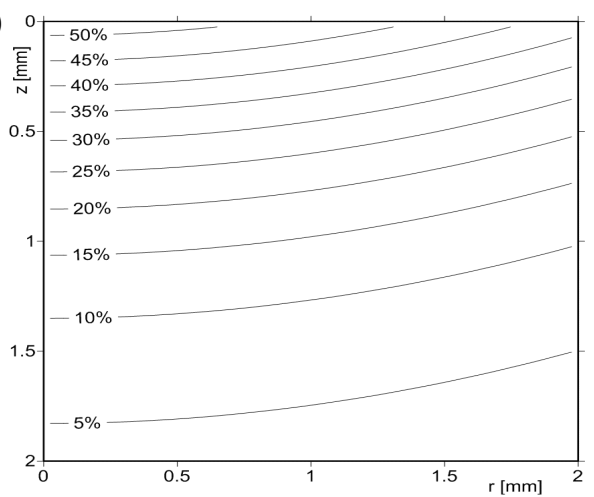

b)

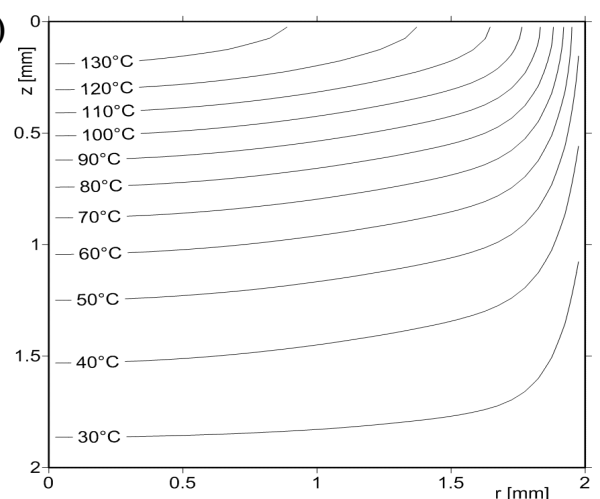

Fig. 2. Isolines for monomer conversion (a) and temperature (b) in the monomer/polymer sub-domain at time $0.25 \mathrm{~s}$ (parameters of the light: $t_{0}=0.25 \mathrm{~s}, I_{0}=0.5$ Einstein $/\left(\mathrm{m}^{2} \mathrm{~s}\right)$ )

a)

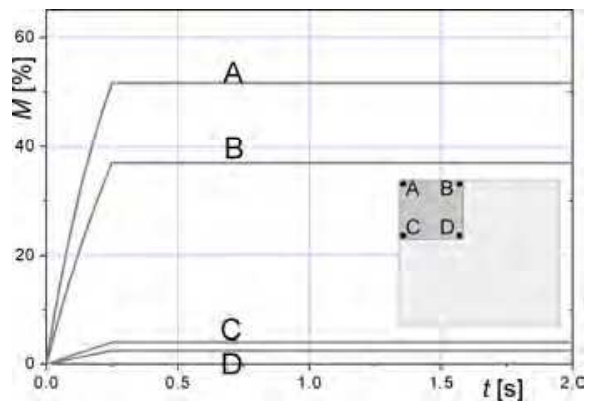

b)

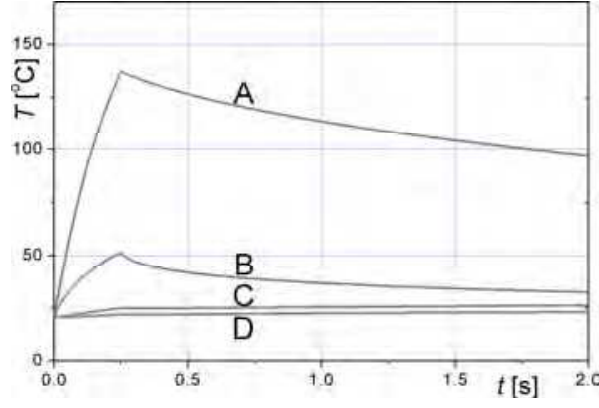

Fig. 3. The kinetics of changes of monomer conversion (a) and temperature (b)

at selected points in the monomer/polymer sub-domain (parameters of the light: $t_{0}=0.25 \mathrm{~s}, I_{0}=0.5 \operatorname{Einstein} /\left(\mathrm{m}^{2} \mathrm{~s}\right)$ ) 
In the second test the values $I_{0}=0.25$ Einstein $/\left(\mathrm{m}^{2} \mathrm{~s}\right)$ and $t_{0}=0.5 \mathrm{~s}$ have been assumed. The results of calculations in Figures 4 and 5 are presented. In the both tests the same light source doses $\left(I_{0} \cdot t_{0}\right.$ Einstein $\left./ \mathrm{m}^{2}\right)$ have been used. Analyzing of obtained results one can note the monomer conversion and temperature rise in the second test.

a)

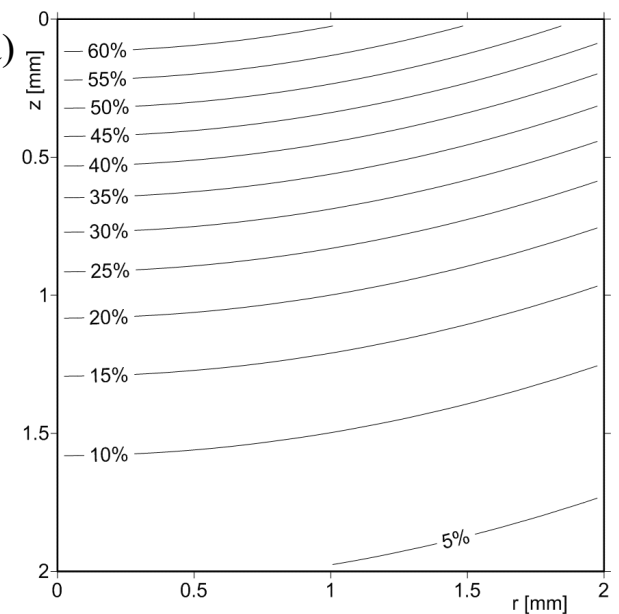

b)

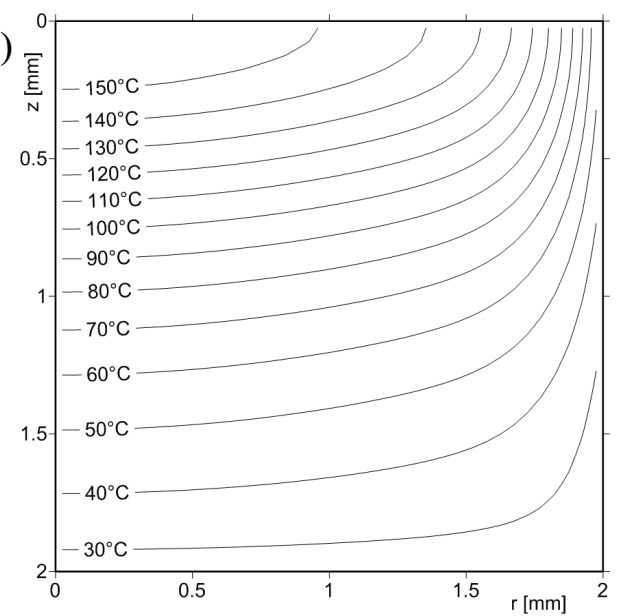

Fig. 4. Isolines for monomer conversion (a) and temperature (b) in the monomer/polymer sub-domain at time $0.5 \mathrm{~s}$ (parameters of the light: $t_{0}=0.5 \mathrm{~s}, I_{0}=0.25$ Einstein $/\left(\mathrm{m}^{2} \mathrm{~s}\right)$ )

a)

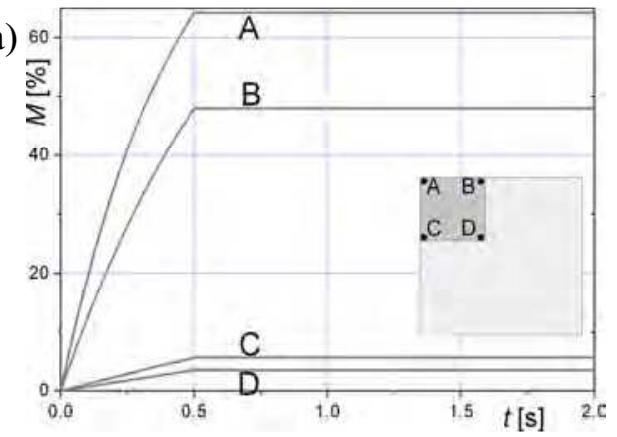

b)

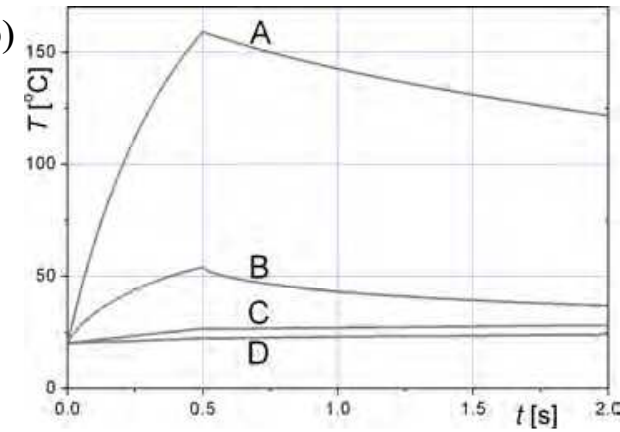

Fig. 5. The kinetics of changes of monomer conversion (a) and temperature (b) at selected points in the monomer/polymer sub-domain (parameters of the light: $t_{0}=0.5 \mathrm{~s}, I_{0}=0.25 \operatorname{Einstein} /\left(\mathrm{m}^{2} \mathrm{~s}\right)$ )

\section{Conclusions}

In the present work, the mathematical model for photopolymerization in the cylindrical domain (2D task) was presented. The polymerization process proceeds in a short time. The effect of the same light source dose on the polymerization and thermal processes is very significant. 
In the future we plan to use numerical simulations for polymerization of lightcurable resin-based composites, which can be used as dental filling materials that are curable by light.

\section{References}

[1] Odian G., Principles of polymerization, $4^{\text {th }}$ ed., Wiley-Interscience, 2004.

[2] Flach L., Chartoff R.P., A computer model for laser photopolymerization, Proceedings of the Solid Freeform Fabrication Symposium, 1997, 155-163.

[3] Perry M.F., Young G.W., A mathematical model for photopolymerization from a stationary laser light source, Macromolecular Theory and Simulations 2005, 14(1), 26-39.

[4] Majchrzak E., Mochnacki B., Numerical methods. Theoretical bases, practical aspects and algorithms, Publication of the Silesian University of Technology, Gliwice 2004 (in Polish).

[5] Mochnacki B., Suchy J.S., Numerical methods in computations of foundry processes, Polish Foundrymen's Technical Association, Cracow 1995.

[6] Szopa R., Siedlecki J., Modelling of solidification using the control volume method, Solidification of Metals and Alloys 2000, 44(2), 349-354.

[7] Tryson G.R., Shultz A.R., A calorimetric study of acrylate photopolymerization, Journal of Polymer Science: Polymer Physics Edition 1978, 17(12), 2059-207. 
